\title{
ОСОБЕННОСТИ КОГНИТИВНЫХ РАССТРОЙСТВ У БОЛЬНЫХ С РАННИМИ ФОРМАМИ ХРОНИЧЕСКОЙ НЕДОСТАТОЧНОСТЬЮ МОЗГОВОГО КРОВООБРАЩЕНИЯ
}

Нургужаев E.C.

доктор медицинских наук, профессор, заведующий кафедрой нервных болезней КазНМУ им. С.Д. Асфендиярова, г.Алматы

По данным Всемирной федерации неврологических обществ, ежегодно в мире регистрируется не менее 15 млн. инсультов (Гусев Е.И., Скворцова В.И., 1995; Верещагин Н.В. 1999). Сосудистая патология головного мозга является одной из основных причин развития острых нарушений мозгового кровообращения и имеет выраженную медико-социальную значимость в связи с высокой смертностью и инвалидизацией. Значительная часть населения страдает и хроническими цереброваскулярными расстройствами в виде хронической ишемии мозга (по МКБ 10) или дисциркуляторной энцефалопатии (ДЭ). При дисциркуляторной энцефалопатии у большой части пациентов, даже при ранних формах возникают когнитивные расстройства, проявляющиеся различными нарушениями высших корковых функций и имеющие прогрессирующий характер. Когнитивный дефицит нередко обусловлен дисфункцией лобных отделов и варьирует от минимальных расстройств до деменции, при этом определяется целым рядом до конца не изученных факторов риска (Гусев Е.И., Скворцова В.И. 2001; Захаров В.В., Яхно Н.Н. 2003.)

Современные терапевтические методы лечения ДЭ, базирующиеся на принципах энергокоррекции и нормализации метаболизма нервных клеток, включают лечение сердечнососудистых расстройств, стабилизацию уровня артериального давления, улучшение церебральной микроциркуляции.

Важным направлением в лечении больных с когнитивными нарушениями при ДЭ является нейропротекторная терапия.

Поиск новых лекарственных средств, новых подходов в лечении и реабилитации больных этой категории является важной заe-mail: erkinnurgujaev@mail.ru дачей современной медицины. Нами для лечения больных с ДЭ и когнитивными расстройствами был использован препарат фосфокреатинин (Лайботен), который хорошо зарекомендовал себя и подтвердил свою высокую эффективность (Асадуллаев М.М. и соват. 20012).

\section{Материалы и методы исследования.}

В исследование включены 41 больной с ДЭ I и II стадии различного генеза с легкими и умеренными когнитивными нарушениями, с давностью заболевания от 10-15 лет. Возраст пациентов составил от 50 до 73 лет (средний

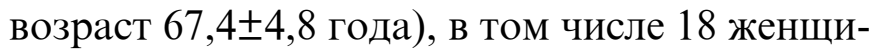
ны $(43,9 \%)$ и 23 мужчин $(56,1 \%)$. Работа проведена на базе кафедры нервных болезней Казахского Национального медицинского университета им.С.Д. Асфендиярова в отделении неврологии ГКБ № 1.

Диагноз устанавливался в соответствии с Международной классификацией болезней десятого пересмотра (МКБ 10) и классификацией сосудистых поражений мозга Центра неврологии РАМН (1985 г.). Из исследования исключались пациенты с грубой соматической патологией, пароксизмальными расстройствами сознания, опухолями головного мозга, нейродегенеративными заболеваниями.

У $30(73,2 \pm 6,9 \%)$ пациентов выявлено сочетание артериальной гипертонии с атеросклерозом сосудов головного мозга, у 2 $(4,9 \pm 3,4 \%)$ больных определялось стенозирующее поражение магистральных артерий головного мозга, у $9(22,0 \pm 6,5 \%)$ пациентов выявилась артериальная гипертония. Из сопутствующих заболеваний у $3(7,3 \pm 4,1 \%)$ пациентов определялся сахарный диабет 2 типа (легкое течение), в 4 случаях $(9,8 \pm 4,6 \%)$ диагнос- 
тирована ишемическая болезнь сердца (стенокардия напряжения I функционального класса, без выраженной сердечной недоста-

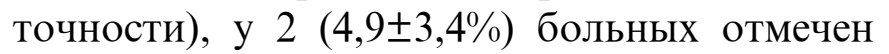
хронический гастрит.

Все больные, методом случайной выборки, были распределены на две сопоставимые по возрасту, полу, клинико-неврологическим проявлениям клинические группы: в первую основную группу вошли $22(53,7 \pm 7,8 \%)$ больных, в контрольную группу $19(46,3 \pm 7,8 \%)$ пациентов. Пациентам основной группы наряду с базовой терапией (антиагреганты, антиоксиданты, по необходимости гипотензивные, диуретики) назначался препарат Лайботен по 1000 мг 1 раз в день внутривенно капельно. Продолжительность терапии составила 15 дней. Больные контрольной группы получали стандартную базовую терапию.

До и после завершения комплексной терапии проводилось нейропсихологическое исследование, анализировались данные неврологического статуса пациентов, изучались параметры электроэнцефалографии, доппле- рографии сосудов головного мозга.

Для оценки состояния высших психических функций у больных с ДЭ проводилось нейропсихологическое исследование по методике А.Р. Лурия $(1974,1976)$ и было направлено на исследование памяти, внимания, двигательных функций, подвижности и истощаемости нервных процессов. Определялась степень когнитивного дефекта (краткая шкала психического статуса - ММСЕ). Синдромальный диагноз легких и умеренных когнитивных нарушений ставился в соответствии с модифицированными критериями P.PetersenTouchon.

\section{Результаты исследования:}

Анализ клинико-неврологических проявлений у пациентов с ДЭ показал достоверный регресс субъективных симптомов на фоне проводимой терапии. У больных основной группы под влиянием комплексного лечения с использованием Лайботена отмечен более выраженный и достоверный регресс клинических симптомов в сравнении с контрольной группой (таблица 1).

Таблица 1

Основные клинические симптомы у пациентов с ДЭ на фоне комплексного лечения (М士м\%)

\begin{tabular}{|l|l|l|l|l|}
\hline \multirow{2}{*}{ Клинические проявления } & \multicolumn{2}{l|}{ Основная группа } & \multicolumn{2}{l|}{ Контрольная группа } \\
\cline { 2 - 5 } & До лечения & После лечения & До лечения & После лечения \\
\hline Снижение памяти и внимания & $90,9 \pm 6,1$ & $54,5 \pm 10,6^{*}$ & $94,7 \pm 5,1$ & $78,9 \pm 9,4$ \\
\hline Головная боль & $86,4 \pm, 3$ & $63,6 \pm 10,3$ & $78,9 \pm 9,4$ & $68,4 \pm 10,7$ \\
\hline Головокружение & $81,8 \pm 8,2$ & $45,5 \pm 10,6^{*}$ & $84,2 \pm 8,4$ & $63,2 \pm 11,1$ \\
\hline Снижение работоспособности & $86,4 \pm 7,3$ & $50,0 \pm 10,7^{*}$ & $89,5 \pm 7,0$ & $73,7 \pm 10,1$ \\
\hline Нарушение ночного сна & $77,3 \pm 8,9$ & $40,9 \pm 10,5^{*}$ & $78,9 \pm 9,4$ & $63,2 \pm 11,1$ \\
\hline Тревога, слабодушие & $36,4 \pm 1,3$ & $22,7 \pm 8,9$ & $42,1 \pm 11,3$ & $31,6 \pm 10,7$ \\
\hline
\end{tabular}

* - различия достоверны $\mathrm{P}<0,005$ с показателем до лечения

К концу лечения у большинства субъективно выявлялось улучшение фона настроения, умственной и физической работоспособности, стабилизации психо-эмоционального статуса в виде снижение тревожности, эмоциональной лябильности.

У больных с ДЭ I и II стадии выявлены легкие и умеренные когнитивные нарушения, что послужило основанием для проведения нейропсихологических исследований в процессе лечения.
Исследование показало негрубые нарушения памяти, внимания, восприятия, ориентации, речи, чтения, письма у пациентов с ДЭ по оценкам ММСЕ. Динамика общего когнитивного дефекта по шкале ММСЕ у исследуемых больных в процессе лечения была положительной, но статистически не значимой (таблица 2). В основной группе средний балл до лечения составил $25,04 \pm 2,23$, после лечения 26,02 $\pm 2,31$ балла $(\mathrm{P}>0,05)$. 
Таблица 2

Оценка когнитивных функций по шкале ММСЕ пациентов с ДЭ (М士м, в баллах)

\begin{tabular}{|l|l|l|l|l|}
\hline \multirow{2}{*}{ Когнитивные функции } & \multicolumn{2}{|l|}{ Основная группа } & \multicolumn{2}{l|}{ Контрольная группа } \\
\cline { 2 - 5 } & До лечения & После лечения & До лечения & После лечения \\
\hline Память & $2,94 \pm 0,44$ & $3,37 \pm 0,48$ & $2,88 \pm 0,42$ & $2,89 \pm 0,43$ \\
\hline Внимание & $3,82 \pm 0,58$ & $3,91 \pm 0,63$ & $3,89 \pm 0,61$ & $3,96 \pm 0,64$ \\
\hline Восприятие & $1,72 \pm 0,28$ & $1,85 \pm 0,29$ & $1,77 \pm 0,27$ & $1,79 \pm 0,29$ \\
\hline Ориентация & $8,89 \pm 1,39$ & $9,03 \pm 1,41$ & $8,82 \pm 1,23$ & $8,86 \pm 1,37$ \\
\hline Речь, письмо, чтение & $7,67 \pm 0,96$ & $7,86 \pm 1,12$ & $7,71 \pm 0,99$ & $7,76 \pm 1,16$ \\
\hline Сумма баллов & $25,04 \pm 2,23$ & $26,02 \pm 2,31$ & $25,07 \pm 2,23$ & $25,26 \pm 2,24$ \\
\hline
\end{tabular}

Проведенное исследование показало хоро- пробы Хэда была выявлена менее выраженная шую переносимость препарата Лайботен у эффективность в контрольной группе пациенбольшинства больных, значимых побочных тов. Если при применении базового лечения эффектов не отмечено. При изучении влияния легкая зеркальность снижается на 15,8\%, то комплексной терапии на зрительно-простран- под влиянием комплексного лечения с испольственную организацию движений с помощью зованием Лайботена на 22,7\% (таблица 3 ).

Таблица 3

\section{Влияние на фоне комплексного лечения с использованием Лайботена на зрительно-пространственную организацию движений $(\mathrm{P} \pm$ м\%)}

\begin{tabular}{|c|c|c|}
\hline \multicolumn{2}{|c|}{ Группы обследованных } & \multirow{2}{*}{\begin{tabular}{|l}
$\begin{array}{l}\text { Частота нарушений по } \\
\text { результатам пробы Хэда }\end{array}$ \\
$50,0 \pm 10,7$
\end{tabular}} \\
\hline до лечения & \multirow[t]{2}{*}{ Основная группа } & \\
\hline после лечения & & $27,3 \pm 9,5$ \\
\hline до лечения & \multirow[t]{2}{*}{ Контрольная группа } & $52,6 \pm 11,5$ \\
\hline после лечения & & $36,8 \pm 11,1$ \\
\hline
\end{tabular}

* - различия достоверны $\mathrm{P}<0,005$ с показателем до лечения

Умеренные нарушения динамической организации движений, выявившиеся в пробах на реципрокную координацию, динамический праксис и графической пробе, значительно уменьшились у больных основной группы, по- лучавших Лайботен, менее значимый регресс наблюдался у больных в группе контроля.

Исследования произвольного внимания, сенсомоторных реакций и мнестических функций (таблица 4) показали значительное умень-

Таблица 4

Влияние комплексного лечения на произвольное внимание, сенсомоторные реакции и мнестические функции у больных с ДЭ $\left(\mathrm{M} \pm_{\mathbf{M}}\right)$

\begin{tabular}{|l|l|l|l|l|}
\hline \multirow{2}{*}{ Метод исследования } & \multicolumn{2}{|l|}{ Основная группа } & \multicolumn{2}{l|}{ Контрольная группа } \\
\cline { 2 - 5 } & До лечения & После лечения & До лечения & После лечения \\
\hline $\begin{array}{l}\text { Проба Крепелина: } \\
\text { количество ошибок }\end{array}$ & $27,2 \pm 6,7$ & $16,6 \pm 5,1^{*}$ & $28,2 \pm 6,7$ & $22,7 \pm 5,6$ \\
\hline Скорость счетных операций, (сек.) & $93,7 \pm 9,7$ & $78,8 \pm 8,3$ & $94,4 \pm 9,8$ & $83,7 \pm 8,8$ \\
\hline $\begin{array}{l}\text { Поиск чисел по таблице } \\
\text { Шульте, (сек.) }\end{array}$ & $80,3 \pm 9,8$ & $66,4 \pm 8,1^{*}$ & $82,3 \pm 9,9$ & $76,4 \pm 8,6$ \\
\hline $\begin{array}{l}\text { Тест «10 слов» (количество вос- } \\
\text { произвед. слов) }\end{array}$ & $5,8 \pm 2,5$ & $8,3 \pm 3,2^{*}$ & $5,6 \pm 2,4$ & $6,7 \pm 2,9$ \\
\hline
\end{tabular}

* - различия достоверны P<0,05 с показателем до лечения 
шение ошибок при выполнении заданий после проведенного курса лечения с использованием Лайботена, возросла скорость счетных операций при выполнении пробы Крепелина. В результате лечения улучшились процессы запоминания, количество воспроизведенных слов в тесте «10 слов», отмечается уменьшение персевераций и контаминаций. Частота изменения «кривой заучивания» на фоне лечения у больных с ДЭ I и II стадии меняется в сторону увеличения нормальной, зигзагообразной форм, при этом снижается частота истощающейся и платообразных форм «кривой заучивания». Отмечены улучшение умственной работоспособности и концентрации внимания, что отразилось в уменьшении среднего време- ни при выполнении пробы Шульте.

В результате проведенного исследования можно сделать вывод о том, что Лайботен на фоне комплексного лечения больных с ДЭ оказывает положительное терапевтическое действие, проявляющееся в сглаживании легких и умеренных когнитивных нарушений, уменьшении общемозговых и астенических симптомов. После проведенного лечения у пациентов улучшились память, умственная работоспособность и концентрация внимания, улучшился общий фон настроения. Все это дает возможность рекомендовать препарат Лайботен для лечения больных с когнитивным дефицитом на фоне хронической ишемией головного мозга.

\title{
SUMMARY
}

\section{FEATURES OF COGNITIVE DECLINE İN PATIENTS WITH EARLY FORMS OF CHRONIC İNSUFFICIENCY OF CEREBRAL CIRCULATION}

\author{
E.S.Nurgujayev \\ Kazakh National Medical University named after S.D.Asfendiyarov, Almata
}

\begin{abstract}
The study included 41 patients with ED stage I and II of various origins with mild to moderate cognitive impairment, with disease duration of 10-15 years. As a result of the study it can be concluded that the Layboten has a positive therapeutic effect against the complex treatment of patients with ED, which manifests itself in smoothing mild to moderate cognitive impairment, reduction of brain and asthenic symptoms. After treatment the patients have improved memory, mental performance and concentration, improved general background mood. All this make it possible to recommend the Layboten for the treatment of patients with cognitive deficits with chronic cerebral ischemia.
\end{abstract}

